\title{
Drone Kazasına Bağlı İlk Adli Vaka Bildirimi; Olgu Serisi
}

\section{First Forensic Case Report Related To Drone Accident: Case Series}

\author{
Sila Yazkan Hira, Taner Akar, Birol Demirel \\ Gazi Üniversitesi Tıp Fakültesi, Adli Tıp Anabilim Dalı, Ankara
}

\begin{abstract}
Özet
Drone, İnsansız Hava Araçları (İHA) arasında en çok kullanılan ve terminolojik olarak en sık tercih edilen bir hava taşıtıdır. İçerisinde bir pilot (drone'u kumanda eden kişi) olmadan, kumanda sistemi sayesinde yerden yönetilebilir ve yönlendirilebilir. Üzerinde taşıyabileceği kamera, silah, radar gibi donanımlar sayesinde özellikle güvenlik, askeri bilgi toplama, gazetecilik ve görüntüleme gibi birçok alanda kullanılmakta ve kolaylık sağlamaktadır. Bu kadar yaygın kullanılması İHA'ların hukuki, sosyal ve güvenlik açısından sorgulanmasına yol açmıştır.

Çalışmamızda aynı drone kazasına bağlı oluşan 3 adli vaka olgusu literatüre katkı amacıyla sunulmuştur. Bugüne kadar tıbbi literatürde sadece iki vaka bildirilmiş olmasına rağmen, haber medyasında insanlarla çok sayıda drone çarpışması vardır. Ayrıca çalışmamız literatür araştırmamıza göre Türkiye'den bildirilen ilk tıbbi bildiridir.
\end{abstract}

Anahtar Kelimeler: Drone; İnsansız Hava Aracı; Adli Olgu; Yaralanma.

\begin{abstract}
Drone is the most commonly used and most preferred term for the air vehicle amongst Unmanned Aerial Vehicles (UAVs). Without an on board human pilot (the person who controls drone), drones can be managed and guided from land thanks to its remote control system. The usage of drones are very versatile since they provide convenience in many areas including security, military information collection, journalism and imaging, thanks to the equipment that can be carried on it such as camera, weapon and radar. This widespread using of drones has led to the questioning of UAVs in terms of legal, social and security matters.

In our study, three forensic cases due to the same drone accident were presented for the purpose of contribution to the literature. Numerous accounts of drone collisions with humans are present in the news media, though only two case have been reported in the medical literature to date. In addition, our study is the first medical report from Turkey according to our research.
\end{abstract}

Keywords: Drone; Unmanned Aerial Vehicle; Forensic Case; Injury.

\section{Giriș}

İHA, içerisinde pilot bulunmayan, yerdeki sabit veya mobil kontrol istasyonundan, radyo frekans dalgaları ile kontrol edilebilen ve üzerinde ölümcül olan veya olmayan bir yük taşıyabilen (kamera, radar, silah vb. araçlar), harcanabilir veya geri alınabilir olabilen hava aracıdır (1). İHA'lar uluslararası literatürde "drone" veya "UAV/UAS (Unmanned Aerial Vehicle/Systems)" olarak tanımlanmakta olup, belirli teknik özellikler dışında gerçekte aynı anlama gelmektedirler. İHA, başlangıçta askeri amaçlarla kullanılmakta iken günümüzde teknolojideki gelişmeler ile boyutları küçülmüş ve drone adı verilen yeni bir hava aracı ortaya çıkmıştır. Drone'ların kullanım alanları askeri ve si-

Sorumlu Yazar: Dr. Sila Yazkan Hira

Gazi Üniversitesi Tip Fakültesi, Adli Tip Anabilim Dall, Ankara

E-mail: dr.silayazkanhira@gmail.com

Geliş: 12.06.2018 Düzeltme: 20.07.2018 Kabul: 10.08.2018 vil amaçlı olmak üzere iki ana sınıfa ayrılmaktadır. Askeri bilgi edinme, görüntüleme, güvenlik, sel, deprem gibi afetlerde olayın erken tesbiti, televizyon programcilığı, gazetecilik, acil ilaç ulaşımı gibi tıbbi durumlar ve çeşitli canlı türlerinin korunmasına yönelik ekolojik çalışmalar, drone kullanımı için başta gelen alanlar olarak sayılabilir (2).

Amerika Federal Havacılık Yönetimince, drone kullanımı için ağırlığının yaklaşık 25 kilogramın altında olmas1, maksimum hizının $160 \mathrm{~km} / \mathrm{saat}$ olması ve maksimum irtifada yerden 122 metre yükseklikte olması ön şartları koyulmuştur (3). Askeri ve sivil birçok alanda kullanılmaya başlanmasıyla drone ilişkili kazalar yaygınlaşmıştır. Bu kadar yaygın kullanım sonucunda drone'ların etik, hukuki ve güvenlik boyutu tartış1ır hale gelmiştir.

\section{Olgular}

Temmuz 2017'de TBMM bahçesinde yapılan 15 Temmuz Şehitleri Anma Töreni esnasında Cumhurbaş- 
kanlığı Koruma Daire Başkanlığı'nın bir güvenlik şirketinden pilotu ile beraber kiralamış olduğu drone tören alanına düşmüş, 3 kişinin yaralanması sonucunda olay adli vaka olarak bildirilmiş ve tarafımızca değerlendirilmiştir. Pilot, ifadesinde; drone'un motor arızasından dolayı düştügünü, olayda kastının olmadığını belirtmiştir. Makalede paylaşılan her üç olguda da hayati tehlike içermeyen basit tıbbi müdahale ile giderilebilen yaralanmalar mevcut idi; ancak drone ilişkili kazaların daha ciddi yaralanmalara sebep olabileceği literatürde daha önce paylaşılmıştır $(4,5)$.

\section{Olgu 1}

25 yaşında kadın hasta, sırtına drone çarpması sonrasında acil serviste değerlendirilmiş, yapılan muayenesinde; sağ skapula üzerinde ve sağ üst kostalarda lateral kısımlarda hassasiyet saptanmış, çekilen toraks tomografisinde akut patoloji tespit edilmemiş, bir süre gözlem sonrasında poliklinik kontrolü önerisi ile taburcu edilmiştir.

\section{Olgu 2}

24 yaşında erkek hasta, başına drone çarpması sonrasında acil serviste değerlendirilmiş, yapılan muayenesinde; verteksten oksipital bölgeye doğru uzanan $2 \mathrm{~cm}$ lik abrazyon tespit edilmiş, yara temizliği ve pansuman sonrasında poliklinik kontrolü önerisi ile taburcu edilmiştir.

\section{Olgu 3}

26 yaşında erkek hasta, parmaklarına drone çarpması sonrasında acil serviste değerlendirilmiş, yapılan muayenesinde; sağ el 3. ve 4. parmaklarda tırnak ve tırnak yata$\breve{g} 1$ hasarı tespit edilmiş, Plastik, Rekonstrüktif ve Estetik Cerrahi Anabilim Dalı tarafindan tedavisi düzenlenerek poliklinik kontrolü önerisi ile taburcu edilmiştir.

\section{Tartışma ve Sonuc}

Drone'lar kumanda ya da uydu sistemleri aracıllı̆ıyla kontrol edilen, dikey olarak kalkış ve iniş yapabilen araçlardır. Drone kullanımının hızlı bir şekilde yayılması, drone kazalarının insidansının artmasına yol açmıştır. Özel hak ihlalleri, etik ve hukuki sorunlar daha çok tartışılmasına rağmen, kötü hava şartları, pilot tecrübesi ve mekanik nedenlere bağlı olarak ortaya çıkan kazalar tehlike yaratabilmektedir. Çalışmamızda, meydana gelen kazanın drone'un motor arızasından kaynaklandığ hangi bir kasıt olmadığı pilot tarafından ifade edilmiştir ancak drone'lar düşerken bile parçalanabilmektedir. Bu durum arızanın tespitini ve Türk Ceza Kanunu'na göre taksirle ya da kasti yaralanma konusunda değerlendirilmelerini zorlaştırabilecek, dolayısıyla bazı kasten yaralamaların da gözden kaçmasına sebep olabilecektir.
Özellikle kalabalık alanlarda, güvenlik amacıyla görüntü elde etmek için drone kullanımı çeşitli riskler bulundurmaktadır. Drone kazalarından kaynaklanan yaralanmalar, drone'un ağırlığına, potansiyel enerjisine, çarpma mekanizmasına ve son derece hızlı dönen pervanelerin etkisine bağlıdır. Küçük olsa da, bu dronlar 160 $\mathrm{km} / \mathrm{saatin}$ üzerinde hızlara ulaşabilir ve bedensel yaralanmaya neden olabilecek bir kuvvet sağlayabilir. Yaklaşık $25-65 \mathrm{~km} / \mathrm{saat}$ hızla hareket eden 500 gr ağırlığında bir drone ile üretilebilen enerjinin yetişkin insan kafatasını kırmak için yeterli olduğu kadavra çalışmalarında gösterilmiştir (6). Bugüne kadar tıbbi literatürde bildirilen iki olgu olmasına rağmen $(4,5)$, haber medyasında insanlar ile çok sayıda drone çarpışması vardır. Ayrıca araştırmalarımıza göre drone kazaları ile ilgili yapılmış adli bir bildirim bulunmamaktadır. Bu yönü ile çalışmamız literatürdeki ilk çalışmadır.

Drone kazası ile ilgili ilk tıbbi makaleyi Chung ve ark. (4) yapmış ve drone çarpmasına bağlı kafatası fraktürü ve buna bağlı süperior sagittal sinüs yaralanması olan 13 yaşında erkek hastayı sunmuşlardır. Drone kazası ile ilgili bir diğer çalışmayı ise Moskowitz ve ark. (5) yapmış, hareket halindeki drone pervanesinin çarpması sonucu sağ göz bölgesinde, burun sırtında, sol kulakta ve sol boyun lateralinde laserasyonları olan 9 yaşında erkek hastayı sunmuşlardır. Çalışmamızda bildirilen her üç olgu da kazayı basit tıbbi müdahale ile giderilebilecek yaralanmalar ile atlatmıştır ancak çalışmamızın ilk adli tıbbi bildiri özelliği taşıması ve olası riskleri göz önüne sermesi aç1sından önemli olduğunu düşünüyoruz.

2920 Sayılı Türk Sivil Havacılık Kanunu'nun 144. maddesi ile kişiye özel alanlar, askeri bölgeler ve havalimanlarında drone kullanımına ilişkin önemli sınırlamalar ve yasaklar getirilmiş olmasına rağmen olayın güvenlik boyutunun halen eksik olduğu kanaatindeyiz.

\section{Kaynaklar}

1. "unmanned aerial vehicle" The Free Dictionary. Available from: https://www.thefreedictionary.com/ Unmanned+aerial+vehicles Erişim tarihi: 24.07.2018.

2. Amukele T, Ness PM, Tobian AA, Body J, Street J. Drone transportation of blood products. Transfusion. 2017 Mar;57(3):582-88. DOI: https://doi.org/10.1111/trf.13900

3. Federal Aviation Administration (2016) Operation and certification of small unmanned aircraft systems. In: 81 Federal Register 42063. Available from: https://www.federalregister.gov/documents/2016/06/28/2016-15079/operation-andcertification-of-small-unmanned-aircraft-systems Erișim tarihi: 25.07.2018.

4. Chung LK, Cheung Y, Lagman C, Au Yong N1, McBride DQ, Yang I. Skull fracture with effacement of the superior sagittal sinüs following drone impact: a case report. Childs Nerv Syst. 2017 Sep;33(9):1609-11. DOI: https://doi. org/10.1007/s00381-017-3485-Z 
5. Moskowitz EE, Siegel-Richman YM, Hertner G, Schroeppel T. Aerial drone misadventure: A novel case of trauma resulting in ocular globe rupture. Am J Ophthalmol Case Rep. 2018 Jun; 10:35-37. DOI: https://doi.org/10.1016/j. ajoc.2018.01.039
6. Yoganandan N, Pintar FA, Sances Jr A, Walsh PR, Ewing CL, Thomas DJ, et al. Biomechanics of skull fracture. J Neurotrauma. 1995 Aug;12(4):659-68. DOI: https://doi. org/10.1089/neu.1995.12.659 